\title{
Entropy in the Management of Labor Potential
}

\author{
S.G. Radko* \\ Russian State University named after A.N. Kosygin (Technologies. Design. Art), Russia, 119071, Moscow \\ ${ }^{*}$ Corresponding author. Email: skif13717@yandex.ru
}

\begin{abstract}
The possibility and expediency of using economic and mathematical tools for reducing uncertainty in labor potential management procedures are substantiated. The methodological problem of obtaining a quantitative measure of uncertainty in the management of labor opportunities of employees is determined. The task of developing tools based on the use of entropy as a measure of uncertainty and acting as a means of regulating the system of labor potential management is formulated. An approach is presented that makes it possible to regulate the system of labor potential management in conditions of uncertainty.
\end{abstract}

\section{Keywords: entropy, uncertainty, labor potential, stuff, stuff management, management decision}

\section{INTRODUCTION}

Entropy analysis provides an acceptable tool for getting a conclusion about the essence of an economic problem from the point of view of ordering of uncertainty, but requires a deep understanding of the processes taking place. Entropy is the expression of a certain conditional value that displays the measure of excessive work during achieving the goal. Therefore, entropy does not have an established concept economically. Entropy is deeply embedded in the system of economic research [1, 2]. In Economics, entropy is a certain quantitative indicator of disorder, acting as a measure of excessive work in achieving the goals set for management representatives. When using the concept of «entropy», we can conditionally distinguish the share of side processes or phenomena that accompany economic, production, and economic activities. This definition does not have sufficient clarity to understand what entropy is in its essence and how deeply it can be embedded in the system of analysis of social and labor relations.

The order of presentation of the methodological problem confirms the relevance of the development of measurement tool, which are a tool for visually displaying the capabilities of employees in the labor sphere, contributing to the formation of stuff with a high quality labor potential. When obtaining a measurement tool that reflects a certain side of the potential, it is necessary to carry out its structured description based on the principles of system analysis. Setting the goal of developing the labor potential, selecting indicators, systematizing them, and predicting the consequences of making stuff decisions are the main stages of the study, which give the most complete idea of the features of regulating the stuff sphere, taking into account the labor opportunities of workers. Therefore, it is necessary to develop a theoretical and methodological approach to understanding the content of labor potential and procedural features of its evaluation. Difficulties in developing this approach are explained by the following reasons.
1. The existence of a sufficiently large number of methods for obtaining a quantitative representation of the object of analysis. In relation to the subject of the study, it is reduced to the choice of methods for determining the components of labor potential in relation to the goals of economic entities. 2. The presence of difficulties in establishing the object of analysis due to the lack of generally accepted (universal) definitions of the main socio-economic categories used in the field of stuff management (labor potential, human capital, intellectual capital). Note that even such a simple concept as stuff management is debatable.

3. The subjectivism of many potential assessments, which brings its large share of uncertainty to the stuff management procedures and causes difficulties in making stuff decisions by senior management.

The concept of «potential» as a category for research is widely represented in various spheres of human activity [3]. To manage labor potential, it is necessary to use an interdisciplinary approach that acts as a separate area of knowledge and is allocated to one of the subsystems of the modern sphere of stuff management. In stuff management, it is necessary to use the achievements of Economics, psychology, system analysis, pedagogy, sociology, and other areas of management that form the basis for making stuff decisions.

In the practice of stuff management, the practice of assessing the stability of socio-economic systems is common [4]. Scientific research is being conducted that addresses problematic issues of the quality of stuff management and its capabilities in the labor sphere [5, 6]. Therefore, it is always relevant to develop technical and economic indicators for analyzing the labor opportunities of employees in various areas of human economic activity. Competent stuff management with the priority of development of labor opportunities of employees is facilitated by the presence of a measurement tool that makes it possible to obtain a variety of assessments related to the quality characteristics of the stuff. Such assessments allow us to get an idea of the degree of uncertainty in the labor sphere and assess the feasibility of making stuff decisions 
related to key aspects of the development of the stuff management system.

\section{ENTROPY IN THE MANAGEMENT OF HUMAN CAPACITIES - PROBLEM STATEMENT}

Labor potential occupies a special place in a number of factors that determine the possibility of market regulation, which affects both the manifestation of uncertainty and its dynamics. Let's turn to the problem of obtaining a quantitative measure of uncertainty in labor potential management procedures. There are properties of entropy that can give a general idea of it. These properties are widely known and can be summarized as follows.

1. In closed systems, entropy increases.

2. The more freedom of action, the faster the entropy grows. These properties are significant from the point of view of developing the goal of obtaining a convenient tool for regulating the labor potential management system. Entropy and freedom in the management of labor are interrelated. Freedom in decision-making accumulates entropy, which can lead to a crisis and the destruction of the system. Thus, it is desirable to have information about the limits of freedom in decision-making, which is always an urgent task for the sphere of labor. In economics this attitude conflicts with the views that the market itself regulates supply and demand as applied to the field of labor. The question of determining the labor potential as a socio-economic category is debatable [7].

Based on studies of labor potential, the main problems related to it, are formulated.

1. There are differences in the definition of labor potential. Different authors use inconsistent definitions that often contradict each other.

2. There is no generally accepted list of structural components of labor potential, on the basis of which it is possible to get a clear idea of its internal content.

Based on the fact that there is no generally accepted definition of labor potential, it is difficult to determine its content. In the scientific literature, it is customary for indicate that the labor potential acts used to achieve the goals set by an enterprise or an individual employee. For the labor potential at the level of the business entity, we note the following definition [8]

Labor potential is the ability of employees based on professional knowledge, practical skills, personal and psychophysiological characteristics to realize the goals of the enterprise with proper material, technical, information and organizational support for the labor process.

This definition fully reveals the features of the structure of labor potential. Since it is quite voluminous, it is possible for practical purposes to use its abbreviated version.

Labor potential is the ability of employees to realize the goals of the enterprise with proper material, technical, information and organizational support for the labor process.
This definition is optimal in terms of representing the content of the labor potential. The definition shows that it is the ability of employees is the fundamental for performing the labor tasks assigned to employees.

The labor potential determines the ability of a particular employee and labor collectives to perform the tasks assigned to them. An employee uses a variety of personal qualities when performing work, which usually include knowledge, skills, professional skills, psychological characteristics, etc. The labor potential is usually divided into professional-qualification and personal. Professional and qualification qualities are acquired in the course of study and with the gradual acquisition of experience, personal characteristics are given by nature. Therefore, the labor potential has a complex structure that includes a set of groups of different components that determine the employee's ability to successful work activity.

Consider the understanding of the process of development of labor potential, which is focused on achieving compliance with the included in potential personal, psychophysiological or professional characteristics of workers of the main goals of the enterprise. The level of development of labor potential is characterized by the level of development of components characterized by technical and economic indicators in the accepted units of measurement.

Considering the uncertainty in the labor sphere, you should determine which factors contribute to the growth of entropy (increasing uncertainty and chaos), which on the contrary, allow you to reduce the uncertainty factor. One of the tasks of entropy analysis is to obtain a tool that allows you to determine the moment of bifurcation in the labor potential management system, i.e. the period when any irreversible changes occur that threaten to transition to a crisis state. The research process can be divided into two areas:

1) determination of the entropy of the labor potential management system, which determines the possibility of its targeted regulation;

2) determining the entropy of labor potential as an integral system consisting of many components, i.e. determining the crisis moments of its state, in which the labor potential changes critically.

To regulate the labor potential management system, it is convenient to determine the moments in the dynamics of its development, after which the labor opportunities of employees pass into a new qualitative state. It is important that after such a change, the system cannot return to its previous state. This means that the levers of influence on regulated structures should be changed by making other management decisions. Hence, under the entropy of the labor potential management system, we will understand a quantitative measure of uncertainty that characterizes the labor potential management system and the possibility of regulating it taking into account the uncertainty factor. For the management team, it is not even the possibility of regulation that is of interest, but the definition of bifurcation points where abrupt or irreversible changes take place. Thus, it is possible generate the critical 
concept of the entropy of the system of labor potential management.

The critical entropy of the labor potential management system is understood as the amount of uncertainty at which the labor potential management system enters a fundamentally new qualitative state. This condition will not necessarily lead to any negative consequences, but will require decisions that may be of a fundamental nature.

It can be stated that the quantitative assessment of entropy provides ample opportunities for analysis. The question is how to interpret the estimated values obtained. The problem of interpreting the results of the analysis is particularly evident in relation to socio-economic categories, such as labor potential. There is a methodological problem which is in obtaining a quantitative measure of uncertainty in the procedures of management of labor opportunities for employees in the sphere of labor economy The presence of a measurement tool makes it possible to reduce the negative factor of uncertainty in the management of labor potential stuff and making timely and effective stuff decisions.

\section{Features of representation and understanding of the structure of labor potential.}

Technologies of stuff management, which act as a set of techniques and methods for hiring staff, are constantly becoming more complex in a market environment full of uncertainty. Effective stuff management is focused on full the use of employees abilities. It concerns, among other things, the development of personnel labor opportunities in order to obtain the best work results. Stuff decision-making is based on taking into account the risks associated with stuff management and arising from the uncertain nature of human activity. Uncertainty in stuff management leads to relatively low manageability of organizational behavior of employees. In General, these features complicate the management of the labor sphere. This directs top management to develop the qualification and professional component of economic activity, taking into account the presence of an uncertainty factor. Thus, it can be stated that the development of labor potential is a complex activity due to the fact that it is accompanied by a constant presence of stuff risks and significant uncertainty.

In the theory of labor potential, the concept of «component of labor potential» has become widespread. By definition, the component is an integral part of the labor potential and characterizes professional knowledge, practical skills, personal and psychophysiological characteristics of employees, reflecting the ability of stuff to perform the professional tasks.

Solving the problem of identifying components and determining their relationships with the organizational environment allows you to bring into a single system the goals of the production system and its capabilities to achieve them, implemented through constant regulation of the labor management system.

On the basis of a combination of the concepts of «professional knowledge» and «practical skills», the content of the labor potential is specified. In order for this content to get its practical implementation, you should have an idea of the structure of the labor potential. The structure is usually understood as the mutual location and connection of the components of an object. The components of labor potential are logically related. This means that the set of components and their relationships form the structure of labor potential. Thus, the combination of people's abilities, knowledge and skills represents the part of the labor potential that acts as an integral element of its structure. There is a need to formulate a definition of the structure of labor potential.

The structure of labor potential is the ratio of components that reflect professional knowledge, practical skills, personal and psychophysiological characteristics related to people's abilities in the field of labor activity.

Difficulties in understanding the content of labor potential lead to complexities in interpreting the term «development of labor potential». Therefore, we give the following definition. The development of labor potential is understood as the achievement of compliance of the components that determine the target direction of the company's activities with its main goals (mission). The level of development of labor potential is characterized by the level of development of components, expressed by the values of their indicators in the accepted units of measurement.

When formulating the definition of labor potential, it is necessary to identify the most significant components of labor potential. The essence of the components must be understood as far as the problem of assessing the labor potential needs to be solved. Differentiation of approaches to understanding the essence of labor potential allows increasing the reliability of research results. It also contributes to the creation and development of tools related to the analysis of the total real and potential human labor opportunities.

Personal, psychophysiological and professional characteristics should be chosen that allow you to get the most complete picture of the goals of work activity. In employment potential include education, training, qualification, gender, age, and value orientation of work, etc. Than more included in the structure of the labor potential of the various components, the more difficult to define therein the specific features of the people, manifested in the workplace.

Ordered representations of personal characteristics that are components of labor potential are mentioned in various sources. The scientific and educational literature contains components such as intelligence, creativity, health, education, professionalism, morality, activity, and organization.

Despite the fact that attention has been paid to the development of labor management systems for a long time, there are differences in the submission of structure of labor potential. Various characteristics of employees professional, personal, and psychophysiological-are used in determining the labor potential. In the literature, affecting the problems of research of labor opportunities of employees, various descriptions of the structure of labor potential are given. Characteristics of employees that reflect the ability of the staff to perform work tasks, act as a 
category of «components of labor potential». The components include professional-qualification, personal and psychophysiological characteristics that reflect the ability of stuff to effectively perform the production tasks assigned to them.

Existing opinions about the nature of labor potential differ significantly. Nevertheless, there is an array of various publications that address the problems of understanding the labor potential, which reveal a common approach to it. According to it, the labor potential includes a set of various components, the list of which can be increased to an acceptable number, convenient for specific research or practical purposes. The examined set allows you to adjust the tasks associated with labor potential.

To get a complete picture of the characteristics of employees who act as components of labor potential, you should have a complete list of them (a fragment of the list of components is presented in table. 1).

Table 1. Fragments of the list of components

\begin{tabular}{|c|c|}
\hline № & Component \\
\hline 1 & Accuracy \\
\hline 2 & Activity \\
\hline 3 & Ambitiousness \\
\hline 4 & Analytical mind \\
\hline 5 & Vigilance \\
\hline 6 & Thrift \\
\hline 7 & Unselfishness \\
\hline 8 & Impartiality \\
\hline 9 & Trustworthiness \\
\hline 10 & Prudence \\
\hline 11 & Polite \\
\hline 12 & Strictness \\
\hline 13 & Authoritativeness \\
\hline 14 & Attention \\
\hline 15 & Attentiveness \\
\hline$\ldots \ldots$ & 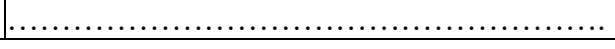 \\
\hline
\end{tabular}

The list of components of labor potential usually includes only the main ones that the stuff specialists have an idea about. Based on the list of main components, you can get an idea of the state of labor potential. By expanding the list to the desired level, you can get an additional representation of the workforce's capabilities.

It is convenient to classify the components of labor potential into different groups. The main ones are psychophysiological, qualification and personal. Psychophysiological reflect a person's inclinations, health, talent, etc. Qualification includes knowledge and skills obtained in the process of acquiring professional skills. Personal, not directly related to work, characterize a person as a developed personality, including curiosity, mobility, spirituality, etc.

Looking at these problems, you can see that they are interrelated. In the absence of a clear and generally accepted definition of labor potential, difficulties naturally arise when describing its structure. Having an idea of the structure of any socio-economic category, especially such as labor potential, is a prerequisite for developing analysis tools.

\section{ENTROPY AS A MEASURE OF UNCERTAINTY IN LABOR POTENTIAL MANAGEMENT}

Let's consider the labor potential of employees in the form of a distribution of the indicator taken as a standard when presenting its components. For workers this indicator is convenient to consider the volume of output for the management team - terms of realization of managerial decisions, etc. For each group of employees for which labor potential is measured, we need to find indicators that have a unit of measurement which would allow to judge about the efficiency of work with a maximum degree of confidence. Let's focus on some calculations related to entropy analysis.

In information theory, the value of entropy as a measure of the uncertainty of outcomes is determined by the Shannon formula.

$$
\mathrm{H}=-\sum_{i=1}^{n} P_{i} \log _{2} P_{i}
$$

This formula is widely presented in the literature and does not require additional explanations.

In economic research, the value of entropy as a measure of relative concentration is determined by the formula from [9]:

$$
\mathrm{H}_{\ni}=-\sum_{i=1}^{n} l_{i} \lg l_{i},
$$

where $l_{i}$ denotes the probability of occurrence of the $i$-th event.

Entropy analysis is widely used in information theory. Due to its spread, entropy analysis tools can be extrapolated to the field of labor, in particular, the theory of labor potential. The most important question for the theory is the number of components and the features of their choice from the entire set of employee qualities. Groups of employees are formed under the influence of management decisions. The actual development of components, characterized by their indicators, is determined by the possible outcomes of the distribution of the total labor potential between employees. However, to get an idea of the distribution of efforts of representatives of higher and middle management, management actions can be considered as the result of a random phenomenon with $n$ different outcomes and with the probability of the $i$-th outcome equal to $l_{i}$.

Each possible outcome can be set in accordance with the probability of its implementation, set by the parts or shares of the average indicator of labor potential in the total result of labor activity. If the possible outcomes of the implementation of the component development levels would be denoted through $i_{1}, \ldots, q_{i}, \ldots, q_{n}$ and the 
corresponding them probabilities through $l_{1}, \ldots, l_{i}, \ldots, l_{n}$, we obtain a distribution of components characterized by certain ratios $l_{i}$ и $q_{i}$ of the considered labor potential.

Let's denote the actions of the management team related to the management of labor potential through $q_{1}, \ldots, q_{i}, \ldots, q_{n}$, the probabilities corresponding to the successful outcome of decisions through $l_{1}, \ldots, l_{i}, \ldots, l_{n}$. We get a description of the distribution of actions of the management team during making decisions in the procedures for managing labor potential.

In this case, the average amount of information (entropy) is derived from the actions of the management team for one result of a random variable.

Here the methodological problem of understanding is manifested of $l_{1}$. In this paper, the probability is taken as $l_{1}$. This is done so that the results obtained correspond to the entropy theory as much as possible. For ease of practical use, it is advisable to derive some other indicator for $l_{1}$, for example, to determine the ratio of the actual value of the indicator to its maximum value, normalized in a certain interval.

With a single outcome, or a single action $\left(q_{i}=1, l_{j}=0\right.$ for all $i \neq j, i, j=\overline{i, n}$ ) the results of the actions under consideration (i.e., the activities of the management team) are determined accurately and the uncertainty is 0 . This means that the effect of decision-making is maximized. Achieving results in the management of labour potential should correspond to the maximum positive value of managerial effect, defined by the criterion of the goals (e.g., achieving compliance with quality potential and goals in the management of stuff in the procedures of development of labor potential).

As the number of outcomes increases, the uncertainty increases and reaches a maximum at $1=\frac{1}{n}$. Due to the fact that increasing uncertainty is accompanied by a decrease in the effect of management decisions, it can be considered reasonable to conclude that it is possible to represent the relationship between managerial influence and the development of labor potential components using the entropy indicator.

Entropy can be considered as a measure of concentration of management actions, which determines, among other things, the speed of response of the labor potential to current changes. The assumption that it is possible to estimate the effect of management actions by the value of entropy has the following grounds. Entropy turns to zero when one of the outcomes is credible, and the others are impossible (a situation in which the maximum return is observed from a single managerial impact on the component of labor potential). For a given number of States, it turns to the maximum if these States are equally probable, and when their number increases, it increases.

It is interesting to consider a situation in which entropy turns to a maximum if management actions are equally likely. In practice, this means that there are several decision centers. Each of them can make decisions by adjusting the managed system with the same probability. Thus, independent management bodies make decisions with equal probability on one problem, which is either impossible in management systems, or will lead to unbalancing of the management system. So, the statement that for a given number of States, entropy turns to a maximum if these States are equally probable is true.

It is logical to assume that a decrease in the effect of management (no matter how it is expressed) entails an increase in entropy. Accordingly, the risk of a large number of threats and stuff risks will increase [10, 11]. This statement is based on the fact that a complex system like labor potential cannot be managed with a low quality of management, which directly affects the amount of entropy. In the actual practice of management, the coordination of stuff activities is performed by the relevant management structures. They perform their functions by concentrating their efforts to a certain point where management will be optimal. If the concentration of management actions falls below a certain optimal limit, the entropy of the system increases. As a result, the effectiveness of decision-making is lost, which is especially often observed in communities characterized by the rapid emergence and significant diversity of intercultural communications [12]. Using the entropy indicator will be more convenient for practice if the minimum entropy value corresponds to the condition of maximizing the impact performance. For ease of interpretation of the analysis results, the entropy measure must change in the same direction as the control effect measure. Thus, the condition must be met, according to which the strengthening of the effect of management actions leads to a decrease in the numerical value of entropy, but at the same time an increase in the value of $\mathrm{H}$. For ease of interpretation, we assume that the measure of entropy changes in the opposite direction from the value of the effect of management actions. Minimum entropy means that there is a maximum effect of management actions at a certain point of their application.

When directly using the entropy value to evaluate the effect, it should be borne in mind that the inverse relation under study makes it difficult to interpret the resulting measure of the phenomenon.

It is possible to consider entropy as a measure of regulation of the labor potential management system if the tools for determining it make it possible to obtain numerical values over a limited interval. Therefore, for ease of use, it is possible to carry out the appropriate normalization of the entropy index. To do this, you should perform an inversion of the entropy measure using the approach on the interval $[0,1]$, which would give a convenient tool for measuring. Using the expression

$$
x=\lg n+\sum_{i=1}^{n} l_{i} \lg l_{i},
$$

and having normalized it, we get a quantitative measure of the uncertainty of the $\mathrm{K}_{\text {утп }}$, which characterizes the management system and, accordingly, the value of the effect in the procedures for managing labor potential: 
of individual solutions. Sharp fluctuations in the coefficient values will indicate the presence of intermediate options for their adoption, rather than a change in the effect when making individual decisions.

where КЭ potential management in conditions of uncertainty. Consider the following example. In table 2 the values of $l_{i}$ that characterize the probability of obtaining an effect from the implementation of decisions related to the components of labor potential, as well as the obtained values of the coefficient, are presented $\mathrm{K}_{\text {утп }}$.

Table 2. Values of $l_{i}$ probabilities for some variants of implementation of management decisions on components of labor potential

\begin{tabular}{|c|c|c|c|c|c|c|c|}
\hline № & $l_{1}$ & $l_{2}$ & $l_{3}$ & $l_{3}$ & $l_{4}$ & $l_{5}$ & КЭЭ $_{\text {утП }}$ \\
\hline 1 & 0,40 & 0,40 & 0,20 & - & - & - & 0,040 \\
\hline 2 & 0,30 & 0,20 & 0,20 & 0,20 & 0,10 & - & 0,033 \\
\hline 3 & 0,16 & 0,16 & 0,17 & 0,17 & 0,17 & 0,17 & 0,0002 \\
\hline
\end{tabular}

According to the table 2 we can conclude that the closer the distribution of components is to the hypothetical uniform distribution, the lower the entropy value is observed. If the probability distribution is uniform, the coefficient value is КЭ утп effect of making stuff decisions is equally likely. Thus, using the calculation formula $\mathrm{KЭ}_{\text {утп }}$ allows you to get a logical justification of the results based on its values.

The considered approach is especially valuable for studying the knowledge, skills and abilities of employees within the competence approach [13, 14]. The generated list of competencies for employees will show the relationship between professional knowledge and skills of employees and the effect of stuff decisions [15, 16]. A certain relationship between competencies and individual components of employees, taking into account the uncertainty factor, will help to reduce entropy in the procedures for developing practical solutions in the process of stuff management $[17,18]$.

It is possible to consider the labor potential with any number of components and get the coefficient values $\mathrm{K}_{\text {утп }}$ according to their totality, provided that economic and mathematical tools are used to determine the importance of the studied objects $[19,20]$. Taking into consideration the labor potential of an employee with clearly defined components, for example, defined using expert methods, is advisable if the indicators of the components have different units of measurement, which is observed in practice.

Thus, the coefficient $\mathrm{KЭ}_{\text {утп }}$ it is convenient to use as a quantitative measure of uncertainty that characterizes the system of labor potential management when making decisions concerning the development of individual components. Fluctuation of coefficient values $\mathrm{K}_{\text {утп }}$ shows the dynamics of changes in the effect of the implementation

\section{CONCLUSIONS}

Entropy as a measure of uncertainty makes it possible to get a holistic view of the components of labor potential as a whole. The entropy calculation tool is also an analysis tool that helps to structure information related to the development of the workforce and stuff decision-making. The features of using the formula for calculating the coefficient for evaluating the effect of labor management largely depend on the type of source information. The specificity of the information makes it possible to obtain a sufficient number of bifurcation points in stuff management that allow us to assess the state of the system of development of labor potential in dynamics. Obtaining such information can be the goal of the analysis itself, since it is always of interest for the management team to identify decisions that show sharp changes in the effect of their adoption.

It can be stated that in order to reduce uncertainty in the procedures for regulating the number of stuff and the quality of labor potential, it is necessary to assess the performance of the entire stuff management system. The entropy index allows us to interpret the features of regulation of the labor potential management system taking into account the uncertainty factor.

The accuracy of the forecast in the development of labor potential depends on the features of the economic and statistical information used. For the management team, it is not the entropy itself that is of interest here, but how uncertainty and the presence of critical changes in the stuff management system are interrelated, which translate the labor potential into a different state. Thus, employees who are responsible for making stuff decisions can use this approach as a basis for obtaining stuff information based on the use of entropy as a measure of uncertainty and acting as a quality supplementary tool for regulating the labor potential management system.

\section{REFERENCES}

[1]. V.A. Zhebit Entropy as the aspect of the order / chaos concept in the philosophical interpretation of will. All-Russian Institute of scientific and technical information of the Russian Academy of Sciences (VINITI RAN). Economic and socio-humanitarian studies. 2018. № 1(17). P. 76-83.

[2] A.G. Morachevsky, E.G. Firsova Academic Ilya Romanovich Prigozhin (to the 100th anniversary of his birth), Scientific and technical sheets of SPbPU. Natural 
and engineering Sciences. 2017. T. 23. № 2. S. 237 241. DOI: 10.18721/JEST.230222.

[3]. Dictionary of the Russian language: in 4 volumes / RAS, Institute of linguistic research / ed. by A.P. Evgenieva. 4th ed., stereotypical. M.: Rus. yaz., Polygraph resources, 1999. ISBN 5-200-02674-1 (Vol. 2) («Russian language»). ISBN 5-200-02672-5 («Russian language»). ISBN 5-87548-045-9 (Vol. 2) («Polygraph Resources»). ISBN 5-87548-048-3 («Polygraph Resources»).

[4] Stepanova S.M., Sorokina T.Yu. Design of industrial labor flows in order to ensure sustainable socio-economic development of the region. Bulletin of Ivanovo state University. Series: Economics. 2018. № 1 (35). P. 72-73.

[5]. B.M. Genkin, A.Y. Prikhach About the problems of assessment and optimization of stuff, Scientific notes of the Economics section of MANVCH. Russian entrepreneurship as a factor of innovation development in higher education, Under the editorship G.L. Bagiev. Ekaterinburg: Publishing house Ural. state economic university, 1999. Vol. 5.

[6] Potudanskaya V.F., Trunkina L.V. Assessment of labor potential of the enterprise stuff. Business.

Education. Right. Bulletin of the Volgograd Institute of business, 2011, № 4 (17).

[7] N.R. Hodasevich Assessment of labour potential: approaches and methods, Internet-journal «Science of Science»б 2014. №. 6. URL:

http://naukovedenie.ru/PDF/202EVN614.pdf. DOI: 10.15862/202EVN614.

[8] S.G. Radko Labor potential as a socio-economic category. St. Petersburg: Branch of the publishing house «Enlightenment», 2010.

[9] V.A. Afanasiev Specialization and concentration of production in the Shoe industry. M.: Light and food industry, 1982.

[10] Economic and labour risks: monograph / Artem Nikolaev, Olga Sokolov, Anatoly Ivanovich Tajov. Kostroma (Russia) - Berlin (Germany): Publishing house by Fire. state technol. UN-TA and Goetz studies, 2009. 144 P. ISBN 978-5-8285-0472-5.

[11] Golysheva E.E., Stepanova S.M. Resource analysis of economic security of the region: labor component, Bulletin of the Saratov state socio-economic University. №. 3 (77). 2019. Pp. 86-90.

[12] S.G. Ter-Minasova Language and intercultural communication. M.: Slovo/Slovo, 2000. 624 p.

[13] S. Sanghi The Handbook of Competency Mapping, New Delhi: Sage Publications India, 2007. 252 p.

[14] E.A. Prishlyak Competence approach in human resources management // Design, technologies and innovations in textile and light industry (INNOVATIONS-2018): collection of materials of the International scientific and technical conference. Part 3. M.: FGBOU VO «RGU after A.N. Kosygina», 2018. P. 235-239.

[15] Turban E. Decision support and expert systems: management support systems. Englewood Cliffs, NJ, Prentice Hall Publ., 1995, 885 p.

[16] E.I. Pozolotina Methods of forming a model of competencies for a large enterprise, Manager. 2018. T. 9. № 6. P. 68-77. DOI: 10.29141/2218-5003-2018-9-67.

[17] J. Winterton, F. Delamare-Le Deist, E.

Stringfellow, Prototype Typology of Knowledge, Skills and Competences, Thessaloniki : CEDEFOP, 2005. 419 p.

[18] C.K.Prahalad, G.Hamel, The core competence of the corporation, Journal of Intellectual Capital. 2000. №4 pp. 312-327.

[19] V.V. Podinovski The Problem of estimating the coefficients of importance as symmetricallylexicographic problem of optimization, Automation and telemechanic. 2003. №. P. 150-162.

[20]. A.M. Anokhin, V.A. Glotov, V.V. Pavelyev, A.M Cherkashin, Methods of determining the coefficients of importance of criteria, Automatics and telemechanics. 1997. № 8. 